\title{
Myelitis due to Varicella-Zoster Infection in an Adult Immuno- competent Patient at Yalgado Ouedraogo University Teaching Hospital (Burkina Faso)
}

\author{
Dabilgou $A A^{1^{*}}$, Dao $S B A^{2}$, Dravé $A^{3}$, Kyelem $M J A^{1}$, Napon $C^{4}$ and Kaboré $J^{1}$ \\ ${ }^{1}$ Department of Neurology, Yalgado Ouedraogo University Teaching Hospital, Burkina Faso \\ ${ }^{2}$ Department of Radiology, Yalgado Ouedraogo University Teaching Hospital, Burkina Faso \\ ${ }^{3}$ Department of Neurology, Regional University Hospital of Ouahigouya, Burkina Faso \\ ${ }^{4}$ Department of Neurology, University Hospital of Bogodogo, Burkina Faso
}

*Corresponding author: Dr. Alfred Anselme Dabilgou, Department of Neurology, Yalgado Ouedraogo University Teaching Hospital, 03 BP 7022 Ouagadougou 03, Burkina Faso, Tel: 00-226-74-38-42-70

\begin{abstract}
Background: Varicella Zoster Virus (VZV) is a ubiquitous virus and is causing both diseases of varicella and herpes zoster. VZV reactivation may lead to neurological complications, including transverse myelitis. However, transverse myelitis caused by VZV reactivation is rare in immunocompetent patients.

Case presentation: We reported a case of transverse myelitis caused by VZV in an immunocompetent young patient. A 42-year-old man was presented to the Neurology department in June 2019 with the complaints of cutaneous rash, lower limbs weakness and anal and urinary incontinence. The neurological manifestations occurred at twelve days after cutaneous rash. Spine MRI showed extensive intramedullary T2 hypersignal of C6 to C7. White blood cell showed hyperleucocytosis. Cerebrospinal fluid (CSF) showed leukocytosis (40 cells $/ \mu \mathrm{L}$ ) with increased levels of protein $(1.134$ $\mathrm{g} / \mathrm{l})$. CSF culture for bacteria and fungi were negative. The patient was treated with oral acyclovir, corticotherapy and functional rehabilitation. Complete recovery occurred after 4 weeks of treatment.

Conclusions: Transverse VZV myelitis in an adult immunocompetent patient following cutaneous rash is extremely rare in our context. Clinical outcome was favorable after recommended dose of acyclovir, corticotherapy and rehabilitation.
\end{abstract}

\section{Keywords}

Myelitis, Varicella-Zona virus, Immunocompetent, Burkina Faso

\begin{abstract}
Abbreviations
VZV: Varicella Zoster Virus; MRI: Magnetic Resonance Imaging; DNA: Deoxyribonucleic Acid; PCR: Polymerase Chain Reaction; CSF: Cerebrospinal Fluid; MADRS: Montgomery Asberg Depression Rating Scale; HIV: Human Immunodeficiency Virus; IgG: Immunoglobulin G; CD4: CD4 T Lymphocytes
\end{abstract}

\section{Introduction}

Varicella Zoster Virus (VZV) is a ubiquitous virus and causes both diseases of varicella (primary infection) and herpes zoster (reactivation) occur commonly throughout the world [1]. Varicella is highly contagious; it is most commonly seen in children under the age of 10 years in countries where live-attenuated varicella vaccine is not routinely administered [2]. Adults and immunocompromised patients are more prone to severe infections than healthy children [3]. VZV induced neurological complications are reported as $0.1-0.75 \%$ [4]. Among them, cerebellar ataxia and encephalitis are seen frequently while transverse myelitis, GuillainBarre syndrome, meningoencephalitis are rarely observed [5]. However, transverse myelitis is one of the rarest complications, particularly in immunocompetent patients $[6,7]$. The frequency of transverse myelitis during or after varicella infection is $0.3 \%$ [8]. The most reported complications due to varicella infection in

Citation: Dabilgou AA, Dao SBA, Dravé A, Kyelem M JA, Napon C, et al. (2021) Myelitis due to Varicella-Zoster Infection in an Adult Immunocompetent Patient at Yalgado Ouedraogo University Teaching Hospital (Burkina Faso). Int J Trop Dis 4:049. doi.org/10.23937/2643-461X/1710049

Accepted: June 28, 2021; Published: June 30, 2021

Copyright: (c) 2021 Dabilgou AA, et al. This is an open-access article distributed under the terms of the Creative Commons Attribution License, which permits unrestricted use, distribution, and reproduction in any medium, provided the original author and source are credited. 
the Middle East were Central Nervous System (CNS) involvements followed by skin diseases, varicella pneumonia, and gastric diseases $[9,10]$. Previous studies in African setting, notably in Sudan [11], Burkina Faso [12] and Guinea [13] had reported few cases of myelitis, meningoencephalitis and stroke as neurological complications of VZV. In this study, we describe a rare case of transverse myelitis caused by VZV to emphasize the possibility of its occurrence in an immunocompetent subject.

\section{Case Report}

A 42-year-old man was presented to Neurology department of Yalgado Ouedrago University Hospital in June 2019 with the complaints of cutaneous rash, lower limbs weakness and anal and urinary incontinence of 17 days duration. He had sudden onset of generalized pruritus with vesicular eruption disseminated throughout his face, extremities and trunk, but sparing the palms of hands, soles of the feet. The bursting of the vesicles was associated with a high fever $39{ }^{\circ} \mathrm{C}$. Fifteen days later, he felt muscular weakness of the two lower limbs, a decrease in the sensitivity of the lower limbs going back to the thorax and a urinary and anal incontinence. The patient had no known previous history of chickenpox and had never a chickenpox vaccination. Additionally, his wife and daughter developed chicken pox, 2 weeks before disease onset. On admission, the patient had a body temperature at $37.7^{\circ} \mathrm{C}$, a blood pressure at $120 / 60 \mathrm{mmHg}$ with a heart rate of 90 beats per minute and a respiratory rate of 19 cycles per minute. His weight has been estimated at $60 \mathrm{~kg}$. He was fully conscious, oriented; fundi were normal and cranial nerves intact. Upper limbs were normal. Neurological examination revealed severe weakness of the lower limbs (medical research council (MRC) grade 0/5). Ankle and knee jerk reflexes were abolished bilaterally, without Babinski sign. Furthermore, decreased sensation to touch was noticed with $\mathrm{T7}$ sensitive level bilaterally. Vibration, temperature and pinprick sensations were also diminished in lower limbs. There were no signs of meningitis and cerebellar involvement. Dermatologically, there were macular scarred lesions, hyper pigmented, with a hyperpigmented peripheral halo of rounded shape. These lesions vary in size from 2 to $6 \mathrm{~mm}$, well limited with a regular border, with a smooth surface, sometimes isolated, sometimes grouped in a cupboard scattered over all the integuments (Figure 1). Elsewhere, the lymph nodes were free and there were no sphincter disorders. Cervical MRI showing extensive intramedullary $\mathrm{T} 2$ hypersignal of $\mathrm{C} 6$ to $\mathrm{C} 7$. There was no enhancement on T1 after gadolinium injection and Fat saturation. The remainder of T2 hyper signals is related to a truncation artifact. The spine MRI was considered normal (Figure 2 and Figure 3). A clinical diagnosis of transverse myelitis was made.Cerebrospinal fluid (CSF) was clear, colorless and showed leukocytosis ( 40 cells/ $\mathrm{uL})$, increased levels of protein $(1.134 \mathrm{~g} / \mathrm{l})$ and normal glucose at $2.3 \mathrm{mmol} / \mathrm{I}$ (random blood sugar $4.55 \mathrm{mmol} / \mathrm{l}$ ). CSF culture for bacteria and fungi were negative. The VZV PCR in the LCR could not be performed. The hemogram showed a hemoglobin level at $12.7 \mathrm{~g} / \mathrm{dl}$, white blood cells at $7830 / \mathrm{mm}^{3}$ and a platelet level at $362000 / \mathrm{ml}$ and a C-reactive protein at $44.81 \mathrm{mg} / \mathrm{l}$. Renal function tests, liver function tests and urinalysis were all normal. He was negative on HIV testing with
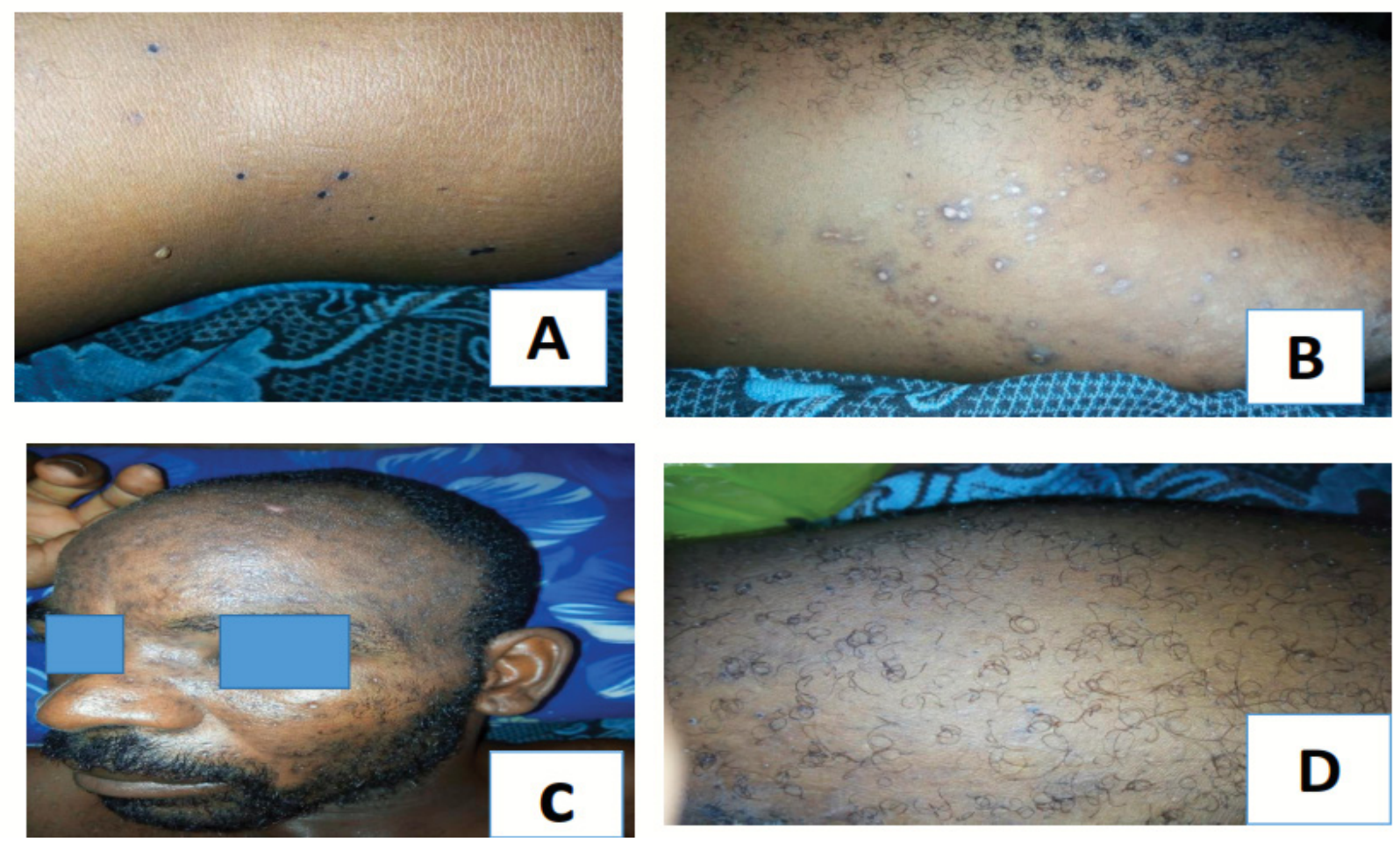

Figure 1: Macula scarred lesions hyperpigmented on the trunk (A, B), on the face (C) and on the leg (D). 

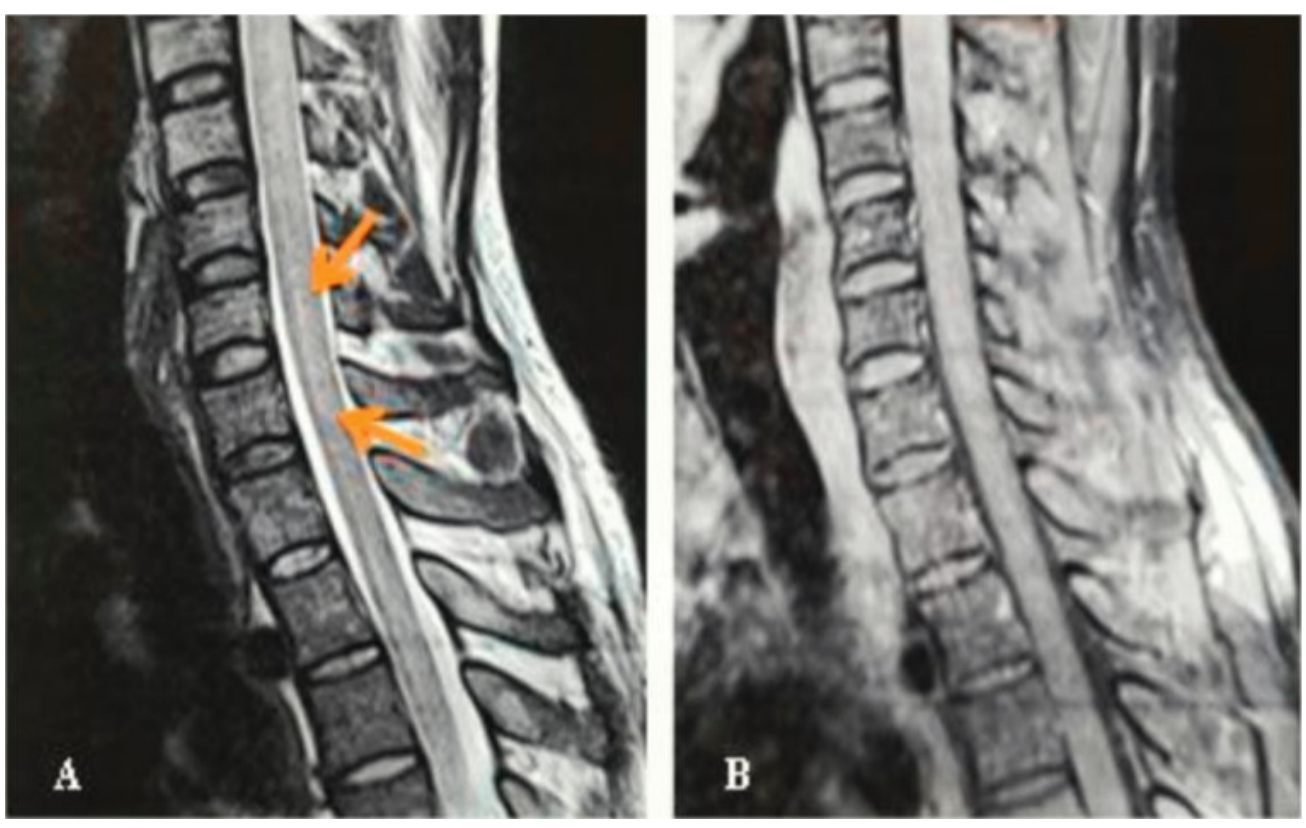

Figure 2: Cervical MRI showing extensive intramedullary T2 hypersignal of C6 to C7 without enhancement on T1 after gadolinium injection and Fat saturation. The remainder of T2 hypersignals is related to a truncation artifact.
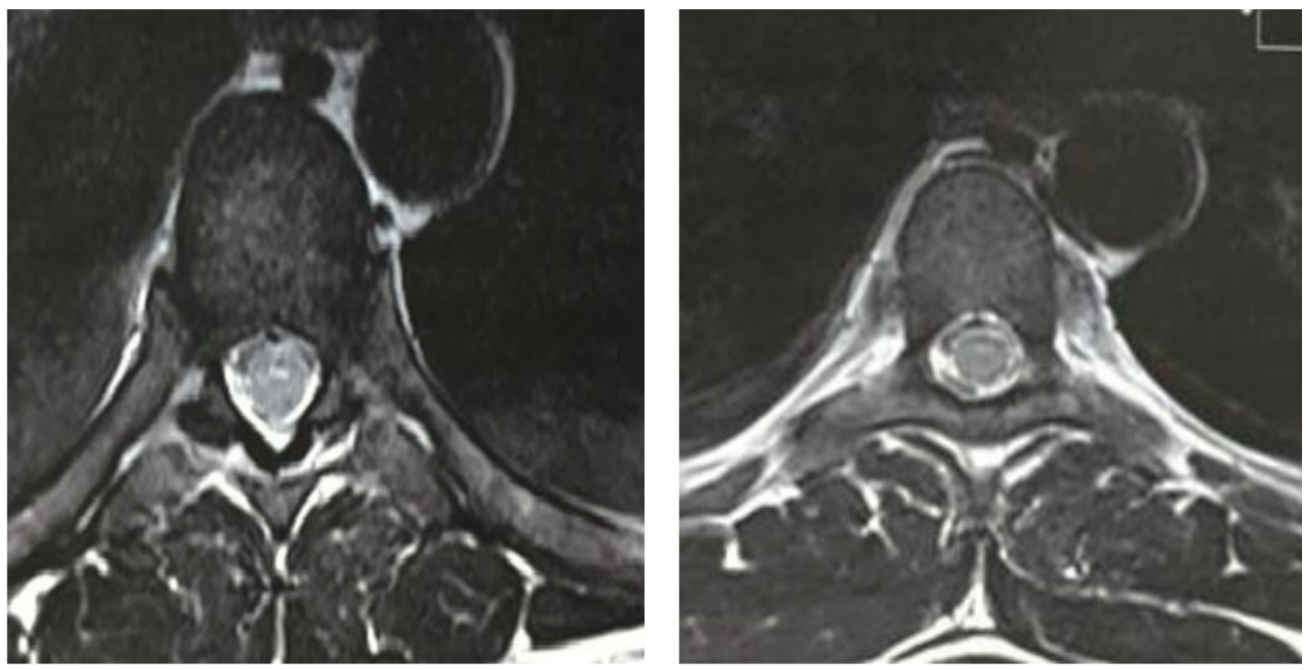

Figure 3: Cervical MRI T1 gado showing normal aspect of the spine (axial coupes).

CD4 count at 1643 cells $/ \mathrm{mm}^{3}$. The varicella etiology was finally retained. Methylprednisolone intravenously 120 mg per day during three days was started 5 days after admission and continued with prednisolone tablets $60 \mathrm{mg}$ per day during 20 days. Oral acyclovir 1000 mg per day during 20 days was started 7 days after admission. Functional rehabilitation was associated during hospitalization stay and after one month. During hospitalized period of 40-day, the patient developed a systemic infection with Escherichia coli on admission day 15 and depressive symptoms on admission day 33 with sadness of mood, suicidal thoughts, anorexia and insomnia. This depression was moderated with a MADRS score rated 20/60. At discharge, the patient presented with apyrexia, spastic paraparesis rated $4 / 5$ and disappearance of depressive symptoms. Complete recovery occurred in 4 weeks of treatment.

\section{Discussion}

This study reports a case of acute transverse myelitis caused by VZV infection in an adult immunocompetent patient. Several cases of VZV myelitis in adult patients have been described in the literature [11,14-21]. Some of these cases concerned immunocompetent patients aged 20 to 79 years [14-19]. In our case, our patient had no defect, the biological balance was normal (blood sugar, hepatic, HIV serology, CD4). Typical presentation of VZV-induced Acute Transverse Myelitis consists of rapidly progressive motor, sensory and autonomic dysfunctions that are usually preceded by a dermatomal rash involving the same spinal level [22]. This typical description was found in our patient. The delay between chicken pox and acute transverse myelitis onset is variable, 15 days with our patient. For Alungal, et al. myelitis can occur with the rash or 
may be delayed for up to 2 weeks [18]. The diagnosis of myelitis is based on spinal MRI which was normal in our patient. This case is found in the literature or up to $40 \%$ of cases have no findings on MRI [23]. Polymerase chain reaction is now the standard methodof diagnosis for many viral CNS infections $[24,25]$. In the case of VZV myelitis, the diagnosis is based on the detection of VZV DNA PCR or the production of VZV IgG in the CSF [14-16,18]. However, in some cases, PCR for VZV DNA and anti-body, viral isolation, and viral culture can be all negative [26]. This confirmation was not necessary in our context because our immunocompetent patient presented a rash typical of chickenpox and had no history of vaccination with VZV. Indeed, diagnostic confirmation was rare in an African context due to the under-equipment of laboratories. For example, in a study from Guinea, authors had found that the 2 cases of VZV myelopathy were diagnosed by blood serology and PCR in blood sample [13]. VZV vaccination is not integrated into the national vaccination program of Burkina Faso. The standard treatment regimen for varicella zoster myelitis is not yet established. However, several authors suggest that treatment with high dose acyclovir and steroid is effective $[14,27,28]$. According to VZV myelitis treatment, early antiviral agents are important to prevent post-herpetic neuralgia [29]. The recommended dose for immunocompetent adult varicella or herpes zoster is $1000 \mathrm{mg} 3$ times daily for 7 days a total dose of $21 \mathrm{~g}$ [30]. In our case, the patient received a daily dose of $1000 \mathrm{mg}$ for 20 days, which is equivalent to the total recommended dose. Corticosteroid therapy was combined as a $120 \mathrm{mg} /$ day bolus for 3 days followed by oral corticosteroid therapy. In some studies, patients were treated with only intravenous acyclovir for 21 days without steroids $[17,19]$. However, the use of acyclovir was not consistent in all series. Thus, Yýlmaz, et al. were not using acyclovir to treat the 2 cases of VZV myelitis; corticosteroid therapy was used in one case [14]. Plasmapheresis can be used during 5 days to improve in case [15]. The prognosis is generally thought to be quite favorable, with complete recovery occurring in about $55-75 \%$ of cases [6,31]. Complete recovery occurred in 4 weeks of treatment. In the study of Yýlmaz, et al. the two patients had fully recovered at 1 year of follow up [14]. The early recovery in our case could be explained by the use of recommended dose of acyclovir.

\section{Conclusion}

TransverseVZV myelitis in anadultimmunocompetent patient following cutaneous rash is extremely rare in our context. Clinical outcome was favorable after recommended dose of acyclovir, corticotherapy and rehabilitation.

\section{Declarations}

\section{Ethical approval and consent to participate}

This study was approved by the local ethical
Committee of Yalgado Ouedraogo University Teaching hospital. All the patients gave their written consent to participate to this study.

\section{Consent to publication}

The patients give his consent to the publication.

\section{Availability of data and materials}

All the data and materials were available with the corresponding authors.

\section{Competing interests}

The authors do not report any conflict of interest.

\section{Funding}

No funding.

\section{References}

1. World Health Organization (2014) Varicella and herpes zoster vaccines: WHO position paper, June 2014. Wkly Epidemiol Rec 89: 265-288.

2. Gershon AA, Breuer J, Cohen JI, Cohrs RJ, Gershon MD, et al. (2015) Varicella zoster virus infection. Nat Rev Dis Primers 1: 15016.

3. Gershon AA, Chen J, Gershon MD (2015) Use of saliva to identify varicella-zoster virus (VZV) infection of the gut. Clin Infect Dis 61: 536-544.

4. Kleinschmidt-DeMasters BK, Gilden DH (2001) Varicellazoster virus infections of the nervous system: Clinical and pathologic correlates. Arch Pathol Lab Med 125: 770-780.

5. Gnann Jr JW (2002) Varicella-zoster virus: Atypical presentations and unsusual complications. J Infect Dis 186: S91-S98.

6. Gilden D, Nagel MA, Cohrs RJ (2014) Varicella-zoster. Handb Clin Neurol 123: 265-283.

7. Amlie-Lefond C, Jubelt B (2009) Neurologic manifestations of varicella zoster virus infections. Curr Neurol Neurosci Rep 9: 430-434.

8. LaRovere KL, Raju GP, Gorman MP (2008) Postvaricella acute transverse myelitis in a previously vaccinated child. Pediatr Neurol 38: 370-372.

9. Al-Mula Abed YW (2016) Varicella-zoster virus associated encephalitis in a patient undergoing haemodialysis. Qatar Med J 2015: 19.

10. Ibrahim W, Elzouki AN, Husain A, Osman L (2015) Varicella zoster aseptic meningitis: Report of an atypical case and literature review. Am J Case Rep 16: 594-597.

11. Elsayed MAM, Aladil O, Elsadig SM, Ahmed MH, Noori SI (2019) Challenging neurological presentations of varicella virus infections in Sudan: Clinical features, imaging and recommendations. J Family Med Prim Care 8: 2161-2164.

12. Ouedraogo JCRP, Ouoba $S$, Savadogo $M$, Savadogo $M$, Nikiema E, et al. (2019) Varicella (chickenpox) morbidity and mortality in hospital: About 19 cases collected at the Yalgado Ouedraogo University Hospital, Burkina Faso. Pan Afr Med J 33: 19.

13. Cisse AF, Ekue MAE, Barry L, Barry SD, Toure ML, et al. (2016) Myelopathies infectieuses et parasitaires aigues en mileu tropical: étude de 26 cas observés au CHU de Conakry. Medecine et Santé Tropicales 26: 439-445. 
14. Yýlmaz S, Köseolu HK, Yücel E (2007) Transverse myelitis caused by varicella zoster: Case Reports. Braz J Infect Dis 11: 179-181.

15. Fernandes BFS, Santos GC, Carmona KC, Vale TC Caramelli P (2014) Varicella-zoster virus longitudinally extensive myelitis in an immunocompetent patient. Rev Bras Neurol 50: 1-3.

16. Takahashi T, Tamura M, Miki K, Yamaguchi M, Kanno A, et al. (2013) Varicella zoster virus myelitis in two elderly patients: Diagnostic value of nested polymerase chain reaction assay and antibody index for cerebrospinal fluid specimens. Case Rep Neurol 5: 81-90.

17. Mahapitiya S, Wijeweera KPI, Hordagoda HL, Bandara WRSM (2018) An uncommon complication of a common disease: Varicella zoster myelitis. Journal of the Postgraduate Institute of Medicine 6: E88 1-5.

18. Alungal J, Abdulla MC, Koya JM, Krishnan R(2014) Varicellazoster virus transverse myelitis in an immunocompetent patient. Int J Res Med Sci 2: 1154-1156.

19. Lee JE, Lee S, Kim KH, Jang HR, Park YJ, et al. (2016) A case of transverse myelitis caused by varicella zoster virus in an immunocompetent older patient. Infect Chemother 48: 334-337.

20. Abbas SA, Helou J El, Chalah MA, Hilal H, Saliba G, et al. (2019) Longitudinal extensive transverse myelitis in an immunocompetent older individual-A rare complication of varicella-zoster virus reactivation. Medicina 55: 201.

21. Paul R, Singhania $P$, Hashmi $M$, Bandyopadhyay $R$, Banerjee AK (2010) Post chicken pox neurological sequelae: Three distinct presentations. J Neurosci Rural Pract 1: 92-96.

22. Gilden D (2004) Varicella zoster virus and central nervous system syndromes. Herpes 11: 89A-94A.
23. Scotti G, Gerevini S (2001) Diagnosis and differential diagnosis of acute transverse myelopathy. The role of neuroradiological investigations and review of the literature. Neurol Sci 22: S69-S73.

24. Read SJ, Kurtz JB (1999) Laboratory diagnosis of common viral infections of the central nervous system by using a single multiplex PCR screening assay. J Clin Microbiol 37: 1352-1355.

25. Iten A, Chatelard P, Vuadens P, Miklossy J, Meuli R, et al. (1999) Impact of cerebrospinal fluid PCR on the management of HIV-infected patients with varicella-zoster virus infection of the central nervous system. J Neurovirol 5: $172-180$.

26. Rosenfeld J, Taylor CL, Atlas SW (1993) Myelitis following chickenpox: A case report. Neurology 43: 1834-1836.

27. Outteryck $O$, Deramecourt $V$, Bombois $S$, MackowiakCordoliani MA, Pasquier F (2007) VZV-related myelitis: A pathophysiological hypothesis. Rev Neurol 163: 89-92.

28. Defresne P, Meyer L, Tardieu M, Scalais E, Nuttin C, et al. (2001) Efficacy of high dose steroid therapy in children with severe acute transverse myelitis. J Neurol Neurosurg Psychiatr 71: 272-274.

29. Ong OLW, Churchyard AC, New PW (2010) The importance of early diagnosis of herpes zoster myelitis. Med J Aust 193: 546-547.

30. Grann Jr JW (2007) Antiviral therapy of varicella-zoster virus infections. In: Arvin A, Campadelli-Fiume G, Mocarski $E$, et al. Human herpesviruses: Biology, therapy and immunoprophylaxis. Chaper 65, Cambridge University Press, Cambridge.

31. Kennedy PGE (2016) Issues in the treatment of neurological conditions caused by reactivation of varicella zoster virus (VZV). Neurotherapeutics 13: 509-513. 